\title{
EDUCAÇÃO E FORMAÇÃO EM CONTEXTO ORGANIZACIONAL
}

\author{
D. C. L. PEREIRA ${ }^{1}$, M. C. P. RAMOS ${ }^{2}$ \\ ${ }^{1,2}$ Universidade do Porto (UP), Faculdade de Economia (FEP) \\ cramos@fep.up.pt ${ }^{2}$
}

Submetido 19/12/2017 - Aceito 06/09/2018

DOI: $10.15628 /$ holos.2018.6757

\section{RESUMO}

Num mercado caracterizado pela crescente instabilidade das relações contratuais, pela complexidade dos processos produtivos e pelas mutações do meio envolvente, a aquisição de novas competências profissionais e a sua atualização permanente através da formação constituem não só fatores de valorização profissional e de empregabilidade, mas também de competitividade organizacional. As organizações são confrontadas com novos desafios de adaptação, eficácia e inovação, em que a gestão das competências e do conhecimento está no centro das suas preocupações, devendo do mesmo modo a formação assumir um cariz de continuidade. Este trabalho assume como principal objetivo a compreensão do processo formativo para uma categoria profissional - vendedor - com o intuito de refletir sobre os contributos multidimensionais da formação inicial versus formação contínua numa empresa multinacional do setor da distribuição alimentar.

PALAVRAS-CHAVE: Formação, empresas, distribuição alimentar.

\section{EDUCATION AND FORMATION IN ORGANIZACIONAL CONTEXT}

\begin{abstract}
In a job market characterised by increasing instability of contractual relations, by the complexity of production processes and changes in the surrounding environment, the acquisition of new professional skills and their permanent updating through training are factors of professional valorisation and employability, but also of organisational competitiveness. Organisations are faced with new challenges of adaptation, effectiveness and innovation,
\end{abstract}

where skills and knowledge management are at the heart of their concerns, and thus training should also be a continuous process. The main objective of this work is to understand the training process of a professional category the salesperson - in order to reflect on the multidimensional contributions of initial training versus continuous training in a multinational company in the food distribution sector.

KEYWORDS: Training, companies, food distribution. 


\section{INTRODUÇÃO}

A dinâmica socioconómica que caracteriza a época atual, associada à globalização dos mercados, progresso tecnológico, difusão da informação, gera inúmeros fatores e contingências que afetam o funcionamento e a eficácia das organizações, requerendo que o seu crescimento e mesmo a sua sobrevivência estejam dependentes da implementação atempada de mudanças em alguns dos seus subsistemas. Perante este cenário, as empresas procuram desenvolver estratégias de competitividade, inovação e adaptação. Partindo do príncipio de que a educação é central em qualquer processo de mudança social, as profundas modificações que têm ocorrido no mundo do trabalho trazem novos desafios à educação e aos saberes profissionais, e é nesse âmbito que se aborda a relação formação-trabalho (Bernardes, 2013; Santelmann, 2017). Tem-se assistido a novas abordagens e práticas de educação de adultos e de formação contínua, relevando desafios da inovação educativa no contexto organizacional (Klarin, 2016) e colocando a educação profissional no centro das inter-relações entre educação e trabalho (Nata, 2016).

Nesse quadro, verifica-se uma valorização crescente do capital humano dentro das organizações, que se traduz num maior investimento em formação e desenvolvimento de competências dos colaboradores, de modo a torná-las mais competitivas no quadro da sua atividade. Assim, as mudanças tecnológicas, socioeconómicas, culturais e políticas das três últimas décadas sugerem o abandono dos paradigmas tradicionais de gestão e a adoção de novos modelos, novas lógicas e novas referências de gestão de recursos humanos e de política de formação, onde a gestão de competências e do conhecimento é o centro das preocupações das empresas (Caetano, 1999; Véro \& Sigot, 2017).

Neste sentido, este artigo pretende contribuir para a compreensão da relevância das dimensões formativas do trabalho e do impacto da formação em contexto organizacional, assim como analisar a forma como é concebida e implementada, tendo em conta os testemunhos de diversos atores, através de inquéritos a vendedores e de entrevistas à responsável de formação e à coordenadora de recursos humanos, constituindo-se como objeto de estudo uma multinacional do setor da distribuição alimentar. Deste modo, assume como principais objetivos a compreensão do processo formativo (conceção e acesso à formação) subscrito a uma categoria profissional vendedor -, procurando simultaneamente perceber como estes profissionais percecionam, participam e vivenciam todo o processo.

\section{REVISÃO BIBLIOGRÁFICA}

De seguida, será construído um quadro teórico que privilegie uma visão multidiscipinar, problematizando-se as questões relacionadas com o trabalho, formação e educação, desde a perspetiva da gestão de recursos humanos e da formação nas empresas à da educação e formação ao longo da vida. 


\subsection{Importância do capital humano das organizações}

Com efeito, tem-se constatado que a procura de fontes de vantagem competitiva sustentável tem incitado ao desenvolvimento de estudos acerca da gestão de recursos humanos no incremento do desempenho e eficácia das organizações. Na economia clássica, o sustentáculo da vida e do funcionamento das empresas estava fortemente ligado ao conceito de "capital-dinheiro"; já na economia do conhecimento, por seu turno, é o capital humano que tem ganho cada vez maior consenso no seio da comunidade académica e empresarial como sendo o seu recurso mais valioso (Ceitil, 2004). As reformas da formação contínua visam cada vez mais fazer do trabalhador o ator principal da sua formação e da sua evolução profissional (Véro \& Sigot, 2017). Consequentemente, tem-se anunciado uma evolução em termos de perfil do colaborador, pela valorização da sua polivalência, do seu comprometimento com a organização, passando pela sua qualificação técnica e capacidade criativa (Fonseca, 2012). Neste sentido, a gestão de recursos humanos, em alinhamento com a estratégia da organização, constitui um instrumento de alavanca em busca de respostas aos principais desafios que se colocam às empresas, nomeadamente a gestão dos impactos da globalização, a maximização do lucro, o potenciar da cadeia de valor do negócio, o desenvolvimento das organizações, a gestão da mudança e a atração e retenção das competências e do capital intelectual das empresas (Urich, 1997, cit. in Monteiro, 2009).

Não obstante, torna-se impreterível a renúncia de uma leitura redutora e unidirecional em torno dos conceitos de "Formação e Desenvolvimento" nas organizações, os quais têm sido percecionados de forma divergente ao longo dos anos. Para Cardoso (1997), o conceito de "formação" pode ser definido como o conjunto de experiências de aprendizagem planeadas por uma organização, com o objetivo de induzir uma mudança nas capacidades, conhecimentos, atitudes e comportamentos dos colaboradores, capacitando-os para assumirem diferentes papéis, em múltiplos contextos, ao longo da vida. Reconhece-se, portanto, que ao longo de todo o período de vida ativa os indivíduos mudam as suas qualificações, o seu posto de trabalho, as suas funções profissionais, sendo por isso imperiosa a abordagem às aprendizagens acumuladas ao longo do seu percurso profissional (Canário, 2000). Apesar de a investigação científica em torno da formação ter assumido maior expressividade nas últimas décadas, é consensualmente aceite na literatura a ideia de que a formação profissional contínua nas organizações surge como um dos principais motores de desenvolvimento dos recursos humanos e do desenvolvimento económico, contribuindo para o aumento da qualificação da mão-de-obra, da sua capacidade de adaptação às mudanças tecnológicas e da redução do desemprego (Dupray, Guillemot \& Melnik-Olive, 2017). Considera-se, portanto, que a teoria do capital humano constitui um ponto de partida para o estudo do impacto da educação e formação no desempenho e promoção dos colaboradores no mercado de trabalho (Ramos, 2003).

\subsection{A formação como política de gestão do potencial humano}

A formação profissional constitui efetivamente um instrumento estratégico de gestão pela intervenção sobre o fator-chave de qualquer organização - os seus recursos humanos (Cardim, 2009). De um modo geral, a formação profissional está associada a processos de aprendizagem 
para o exercício de uma profissão, visando o desenvolvimento sistemático de atitudes, conhecimentos e competências que permitam o desempenho adequado das tarefas em contexto profissional, e podendo assumir modalidades de formação inicial, contínua, de aperfeiçoamento profissional, de reciclagem, de reconversão, etc. (Ramos, 2003, p. 19-22). Constata-se, atualmente, a existência de múltiplas práticas de gestão de recursos humanos que promovem conhecimentos e competências nos colaboradores, os quais, por sua vez, atingem uma melhor satisfação laboral, menos turnover, alta produtividade e melhor tomada de decisão, sendo que esses fatores contribuem amplamente para a melhoria da performance e do sentimento de realização dos mesmos, o que gera uma atitude de satisfação no contexto de trabalho (Cantarello, Filipini \& Nosella, 2012). Assim, investir no indivíduo é, consequentemente, investir na organização, pois, além de adquirir novos conhecimentos e capacidades, fundamentais para aumentar o seu valor, permite às organizações ajustarem-se às necessidades mutantes do contexto (Gomes et al., 2008). A formação profissional apresenta-se, então, como um instrumento de gestão estratégica, na medida em que constitui uma atividade facilitadora da mudança que propicia uma melhor adequação dos recursos humanos a vários níveis, permitindo a atualização do capital humano e a sua adequação aos objetivos mais globais da política da empresa (Cardim, 2009).

Todavia, a educação está mais direccionada para o desenvovimento integral da pessoa, ao passo que a formação é um processo mais pontual e funcional, direcionado sobretudo para a aquisição de competências orientadas para o mercado de trabalho (Cruz, 1998, p. 21). Atendendo aos trilhos percorridos pela investigação, destaca-se que os benefícios decorrentes da participação em ações formativas transcendem largamente o âmbito individual. De acordo com França (2013), a formação acarreta benefícios a vários níveis, nomeadamente: (i) aumenta a capacidade de adotar novas tecnologias e métodos em contexto de trabalho; (ii) melhora substancialmente a motivação e a aspiração dos trabalhadores; (iii) proporciona menor supervisão, na medida em que trabalhadores bem formados necessitarão de menor supervisão, o que constitui uma mais-valia para a organização a nível de tempo e esforço; (iv) reduz os acidentes de trabalho; (v) aumenta a possibilidade de promoção, uma vez que os trabalhadores que recebem formação em contexto de trabalho poderão elevar o nível de competências; (vi) aumenta a produtividade; e (vii) diminui o desperdício de tempo e de recursos, quando os trabalhadores estão devidamente preparados. Assim,

analisar as políticas de gestão de recursos humanos das empresas implica tentar perceber não só o modo como elas são definidas para responder aos desafios da competitividade económica, mas também o modo como contribuem para o desenvolvimento global da sociedade através da promoção da igualdade de oportunidades e da emancipação dos atores sociais (Almeida et al., 2008, p. 3).

Face ao exposto, tem sido inquestionável a importância conferida às formações formal e informal em contexto organizacional, também denominadas por high and low training (Harrison, 2009). Ora, se a formação informal é aquela que não é programada, nem certificada, onde os trabalhadores mais experientes explicam, a título de exemplo, aos mais novos determinados 
procedimentos, a formação formal ou profissional refere-se a uma formação estruturada, planeada e certificada (Torres \& Palhares, 2008). Nesta ótica, o conceito de "não formal" remete para a aprendizagem de competências e/ou regras informais pelos processos simples de observação. No entanto, importa sublinhar que a formação pode materializar-se de diferentes formas e em diferentes contextos, como em sala (salas de formação), on-the-job (local de trabalho), outdoor (ao ar livre), ou por e-learning (conteúdos colocados na Internet). Apesar de a formação mais comum centrar-se na formação em sala, através do recurso a um programa de formação previsto, esta modalidade não é considerada a mais benéfica, uma vez que tende a ser demasiado estandardizada e rigidamente estruturada (Torres \& Palhares, 2008). A gestão da formação procura sobretudo a identificação não apenas de lacunas, conhecimentos e competências, mas assenta também na sua antecipação, de modo a fazer face às necessidades e exigências dos formandos (Camara et al., 2007).

\title{
2.3 Políticas e práticas de formação nas empresas multinacionais
}

Conhecer a estratégia da empresa e o modo como esta se relaciona com a formação é fundamental para perceber se esta decorre da estratégia ou se se confina a necessidades pontuais. Ora, quando integrada na estratégia global de desenvolvimento da empresa, a formação materializa-se em planos, programas e num definido sistema de avaliação. Ao invés, se se pretende que a formação esteja de acordo com a estratégia da empresa e vá ao encontro da resolução ou antecipação dos seus problemas, a função da formação tem de estar integrada na gestão do trabalho e do emprego (Dubar, 2015) e imersa nos próprios processos de trabalho, tal como adverte Bernardes (2008, p.62).

Tem-se constatado, portanto, que na formação impulsionada pelas grandes empresas

\begin{abstract}
são várias as lógicas que podem estar subjacentes e que determinam não apenas a quantidade e o investimento em formação, mas também o tipo de formação e os objetivos visados. Para além da tradição do setor e das questões históricas e culturais da organização, existem outros fatores que influenciam o tipo de formação, como sejam a estrutura e natureza do grupo de trabalhadores, as relações industriais, as atitudes de gestão e as próprias políticas do governo (Bernardes, 2008, p. 62).
\end{abstract}

Percebe-se, então, que as motivações para investir ou não em formação e as opções que as empresas tomam em relação ao processo formativo subordinam-se a vários fatores. Smith e Hayton (1999 cit. in Bernardes, 2013, p. 56) identificaram seis fatores que influem no tipo de formação que as empresas desenvolvem (moderators of training): (i) a dimensão da empresa; (ii) a tradição de formação no tipo de empresa; (iii) a estrutura e natureza dos trabalhadores; (iv) as relações industriais; (v) as atitudes de gestão; e (vi) as políticas de formação dos governos.

Estudos de Bassi e McMurrer (1998 cit. in Bernardes, 2013) demonstraram que as empresas que mais investem em formação têm, entre outros, um volume médio de vendas e de benefícios por 
empregado mais elevado. Além disso, constata-se que a dimensão da organização é um fator determinante para a incidência de formação, na medida em que o nível de organização da função pessoal e da função formação revela um maior tecnicismo no tratamento das questões relacionadas com os seus recursos humanos (Cardim, 2005). Neste quadro, além de fomentarem um volume global de formação superior às outras empresas, as políticas de formação das multinacioais incidem numa maior distribuição dessa formação entre os diferentes grupos profissionais. A sustentar esta ideia, Sousa et al. (2006) consideram que a análise e descrição de funções deveria ser um processo dinâmico e em constante atualização de informação, de maneira a evidenciar as competências necessárias ao desenvolvimento de diversas funções e subsequentes tarefas. Desta forma,

as organizações devem ter um melhor entendimento das necessidades de formação, fazendo o seu diagnóstico e deteção de carências, a nível individual e/ou coletivo, referentes a conhecimentos, capacidades e comportamentos, tendo em vista a elaboração de um plano de formação e desenvolvimento dos seus colaboradores, e proceder a fiáveis e fundamentadas avaliações de desempenho (Ramos, 2003, p. 21).

Posto isto, facilmente concluímos que são as multinacionais aquelas que possuem lógicas distintas e apostam na autossustentabilidade da formação, independentemente de terem ou não apoio (Bernardes, 2013), assim como têm referenciais de formação profissional contínua e subordinação desta às necessidades e aos ritmos do sistema produtivo (Rodrigues \& Alves, 2016).

\subsection{Dinâmica e contextualização da multinacional em estudo}

Com efeito, tem-se constatado que a necessidade de aceleração da dinâmica de resposta do setor da distribuição alimentar face às exigências e tendências de mercado tem incitado as organizações desta área de negócio a uma maior e mais criteriosa intervenção na formação e desenvolvimento dos seus recursos humanos. Especificamente, no que concerne à multinacional em foco, tem registado nos últimos anos mudanças a vários níveis, verificando-se um investimento acentuado no seu capital humano, ou seja, no desenvolvimento e qualificação dos colaboradores. Esta mudança de paradigma deve-se à complexificação do negócio, que, por sua vez, se tornou mais intrincado, de modo a fazer face às mudanças ocorridas no mercado de trabalho. Neste sentido, denota-se uma análise cada vez mais cuidada dos indicadores e uma aposta cada vez mais acentuada nos meios de comunicação internos e externos. A empresa pretende, sobretudo, desenvolver e movimentar os colaboradores dentro da organização para que estes estejam cada vez mais motivados e comprometidos com a empresa. Atualmente, conta com pontos de venda em quase todos os países da Europa, cerca de 10.000 lojas, 140 centros de distribuição, sendo a maior rede de lojas alimentares da linha Discount na Europa, e, no futuro, continuará a desempenhar um papel importante na conquista de novos mercados. Nos últimos anos, tem apostado em medidas de employer branding interno, avocando os colaboradores como seus embaixadores word of mouth, e externo, tendo levado a cabo inúmeras iniciativas com impacto 
nos social media, colaborando com escolas e universidades e sendo presença assídua em feiras de emprego. Em Portugal, dispõe atualmente de cerca de 242 pontos de venda, cinco direções regionais e mais de 4.800 colaboradores com diferentes perfis, de diferentes áreas e com diferentes níveis de experiência.

Uma vez que dispõe de um leque alargado de profissionais, foi-nos somente possível o estudo da categoria profissional de vendedor, o qual é, indubitavelmente, um dos elementos mais importantes da empresa, na medida em que constitui a sua linha da frente e é, por excelência, o profissional de atendimento. $\mathrm{O}$ atendimento começa no vendedor, que é, na maioria das vezes, o único comunicador com o cliente. De um modo geral, o vendedor, nesta organização em particular, executa todo o tipo de tarefas relacionadas com a mercadoria (reposição, atendimento ao cliente, caixa, etc.), assegurando a implementação do conceito de loja de forma autónoma e responsável, utilizando o princípio da simplicidade e produtividade, de acordo com as indicações do superior hierárquico.

\section{METODOLOGIA}

Pretendemos apresentar a formação em contexto organizacional como um instrumento fortemente ligado à decisão estratégica, impulsionador de melhorias na produtividade e motivação dos colaboradores. Assim, definiu-se como objeto de estudo a experiência subjetiva dos vendedores na distribuição alimentar face ao processo formativo (formação inicial vs. contínua) e à avaliação que lhe subjaz, com foco no modo como é vivenciada, significada e integrada nas suas dimensões subjetiva e idiossincrática. Ademais, tentou-se perceber se os colaboradores da organização, após a participação em ações de formação, adquiriam novas competências e conhecimentos com ganhos significativos ao nível do desempenho organizacional. De um modo geral, pretendeu-se aferir mudanças, sentidos e contributos subjacentes ao investimento em formação na organização, bem como compreender os mecanismos no terreno em que esta se mobiliza.

\subsection{Participantes}

No cômputo geral, participaram no presente projeto 130 vendedores, os quais constituíram o seu universo, sendo que i) 122 cooperaram no preenchimento do questionário de investigação e ii) 8 colaboraram na entrevista semiestrutrada aplicada. Concomitantemente, recorreu-se a conversas informais com elementos da organização, nomeadamente a responsável de formação e a coordenadora de recursos humanos, com conhecimento efetivo da realidade estudada, com o intuito de melhor caracterizar os processos formativos adotados pela organização. Para o recrutamento da população da amostra de vendedores, aos quais aplicámos a entrevista semiestruturada, foi estabelecido previamente um critério de inclusão, nomeadamente a antiguidade na empresa ( $\leq 1$ ano). 
Quadro 1: Caracterização da amostra de vendedores inquiridos

\begin{tabular}{|c|c|c|c|c|}
\hline Média & $D P$ & Idade & Min. & Max. \\
\hline 21,6 & 1.9 & & 19 anos & 25 anos \\
\hline \multicolumn{5}{|c|}{ Antiguidade } \\
\hline Média & DP & & Min. & Max. \\
\hline 8.9 meses & 5 & & 4 & 12 meses \\
\hline \multicolumn{5}{|c|}{ meses } \\
\hline Feminino & \multirow{2}{*}{\multicolumn{3}{|c|}{ Género }} & Masculino \\
\hline $62.5 \%$ & & & & $37.5 \%$ \\
\hline 12 Ano & \multirow{2}{*}{\multicolumn{3}{|c|}{ Habilitações }} & Licenciatura \\
\hline $75 \%$ & & & & $(25 \%)$ \\
\hline \multirow{3}{*}{\multicolumn{5}{|c|}{$\begin{array}{l}\text { Ensino Técnico } \\
\text { profissional } \\
(33.3 \%)\end{array}$}} \\
\hline & & & & \\
\hline & & & & \\
\hline \multicolumn{5}{|l|}{ Ensino regular } \\
\hline$(66.7 \%)$ & & & & \\
\hline
\end{tabular}

\subsection{Instrumentos de recolha de dados}

Como meio de operacionalização deste projeto, e coerentemente com os objetivos e natureza do mesmo, foi implementada uma triangulação metodológica, mediante a utilização de diversos métodos de recolha de dados, com recurso a i) análise documental; ii) entrevista semiestruturada; e iii) inquérito por questionário. Deste modo, procedeu-se ao cruzamento de toda a informação recolhida e analisada para possibilitar a criação de inferências passíveis de responder aos objetivos que enformam o presente trabalho.

\subsection{Procedimento}

\subsubsection{Formação da amostra}

Os participantes deste projeto são, entre outros, elementos relacionados com a planificação e operacionalização da formação da Direção Regional Norte de Portugal. Neste sentido, entrevistouse informalmente a responsável de formação, assim como a coordenadora de recursos humanos. 
Na formação da amostra de vendedores foi solicitada a colaboração dos superiores hierárquicos, com vista à facilitação do acesso à população desejada.

\subsubsection{Recolha de dados}

Uma das técnicas de recolha de dados utilizadas foi o inquérito por questionário para vendedores, com enfoque na vivência e experiência subjetiva dos mesmos face ao processo formativo e sua utilidade. Para recolher as representações e vivências de vendedores face ao processo de formação inicial e acolhimento na empresa, foi ainda elaborado um guião de entrevista semiestruturada.

\subsubsection{Tratamento dos dados}

Dado que com este projeto procuramos apreender as experiências, significados e representações, dimensões subjetivas expressas pelos vendedores, uma orientação metodológica que seguisse os princípios da análise de conteúdo pareceu-nos aquela que melhor se ajustaria aos propósitos do presente estudo, tendo sido levado a cabo a análise de conteúdo de Laurence Bardin (1995). Para o tratamento dos dados recolhidos através dos questionários, foi utilizado o SPSS (Statistical Package for the Social Sciences).

\section{APRESENTAÇÃO E DISCUSSÃO DOS RESULTADOS}

Seguidamente, serão expostas cada uma das categorias estruturantes, procedendo à interpretação qualitativa dos significados e sentidos que podem configurar.

Categoria A - Acolhimento na empresa

A primeira categoria em análise reporta-se à significação que os intervenientes conferem ao processo de acolhimento na empresa. Constitui-se premente contemplar as inúmeras vantagens associadas à participação no evento de boas-vindas, o qual se destina à receção de novos colaboradores. Assim, a maioria dos participantes enfatizou o convívio e a socialização que se proporcionou no evento como sendo elementos facilitadores do processo de acolhimento na empresa. Outros entrevistados, porém, enalteceram a possibilidade de os novos colaboradores se inteirarem de informações gerais da empresa (missão, valores, visão, políticas), assim como a clarificação de papéis e formas de resposta adequadas, permitido um ajustamento de expectativas e alinhamento futuro face aos objetivos individuais e organizacionais. De facto, um programa de interação e de acolhimento tende a alavancar resultados amplamente satisfatórios para os participantes e, por conseguinte, para a organização. De acordo com Canário (1997), quanto maior for o alinhamento do colaborador com a visão, missão e valores da organização, maior será a sua contribuição para o crescimento da empresa e o desenvolvimento enquanto profissional. É consensualmente aceite a ideia de que este processo se afigura determinante no que diz respeito ao percurso e retenção do colaborador na organização (Chiavenato, 1998). Assim, uma socialização organizacional eficaz e boas relações sociais no trabalho podem reduzir o nível de 
stress do recém-chegado ao minimizar as diferenças percebidas entre as expectativas criadas pelo colaborador e a realidade organizacional (Thomas \& Lankau, 2009).

\section{Categoria B - Acolhimento e integração em loja}

No que se refere à segunda categoria em análise, esta abarca a forma como os vendedores conceptualizam os processos de acolhimento e integração em contexto de trabalho. Os dados da literatura são congruentes ao evidenciarem que o processo de integração implica um acompanhamento personalizado durante um determinado período de tempo, tendendo a ser mais longo que o do acolhimento, incitando o novo colaborador à aquisição de conhecimento sobre a função, as técnicas envolvidas e as pessoas com quem se vai relacionar na organização (Cunha et al., 2010). A análise dos resultados permitiu verificar que todos os colaboradores, aquando do seu ingresso em contexto de trabalho, levaram a cabo um conjunto de ações preconizadas pela empresa. No que diz respeito à avaliação subjetiva do primeiro dia de trabalho, verificamos que todos os participantes o avaliaram positivamente, sendo que esta avaliação se apresenta, em parte, ancorada na análise positiva que aduzem em relação às equipas que integraram e nas suas caraterísticas distintivas, como a acessibilidade, entreajuda e atenção manifestadas para com o recém-chegado. Verificou-se, então, que a dimensão informal do processo assume, aqui, alguma relevância e materializa-se através de diligências entre os diversos atores organizacionais.

Categoria C - Processo de formação inicial de vendedor

Quanto à abordagem do processo de formação inicial de vendedor, verificamos que a maioria dos participantes o considera equilibrado e ajustado às suas necessidades formativas e ao seu ritmo de apredizagem. Os planos de formação são individuais e costumizados, na medida em que atendem às necessidades de desenvolvimento de competências identificadas para cada colaborador. Além disso, verificamos que os colaboradores atribuem especial relevo ao período de observação no processo de formação inicial, considerando que deverá ser facultado o tempo necessário para observar, apreender, assimilar e questionar técnicas, procedimentos e os demais aspetos relacionados com a dinâmica das lojas. No que concerne à avaliação subjetiva do formador de loja, tentou-se perceber a forma como os participantes qualificam este agente interno, que assume um papel preponderante no acolhimento e integração destes na empresa. 0 formador de loja, grosso modo, está incumbido de ensinar ao novo colaborador conceitos e procedimentos gerais em contexto de loja. Neste seguimento, verificamos que todos os participantes procederam a uma avaliação positiva do mesmo, fazendo referência às características pessoais, competências pedagógicas e profissionais. De acordo com Thomas e Lankau (2009), o mentoring constitui uma técnica com impacto significativo no processo de socialização, na medida em que o desempenho do mentor tende a proporcionar experiências mais positivas ao novo membro, instigando-o a novos desafios e potenciando efeitos de caráter motivacional. 
Categoria D - Empresa como entidade empregadora

A última categoria em análise abarca a forma como os colaboradores avaliam, na sua generalidade, os processos de acolhimento e integração adotados, dando-lhes oportunidade de sugerir soluções para a melhoria dos processos. Além disso, pretende-se reunir elementos que possam avaliar a empresa enquanto entidade empregadora, tendo em conta a experiência subjetiva de novos colaboradores. Com base na análise dos resultados, verificamos que todos os participantes evidenciaram uma imagem positiva da empresa, pelo que não foram mencionados quaisquer aspetos negativos. Este balanço global positivo é sustentado pela atratividade dos salários, horários de trabalho flexíveis, boas perspetivas de progressão na carreira, sensibilidade da empresa face às necessidades dos colaboradores e pelas boas condições de trabalho proporcionadas. No seguimento das abordagens já expostas, reforçamos a premissa, amplamente divulgada na literatura de que o processo de socialização prossegue após o ingresso do recémcontratado nas atividades de acolhimento, prolongando-se durante todo o período do indivíduo na organização (Chiavenato, 1998).

\subsection{ANÁLISE DESCRITIVA DOS RESULTADOS DOS INQUÉRITOS ADMINISTRADOS AOS VENDEDORES}

Com a aplicação do questionário sobre a satisfação dos participantes face à qualidade das ações de formação promovidas pela empresa, e consequente avaliação da sua eficácia em contexto de trabalho, verificamos que, no cômputo geral, os vendedores da amostra em estudo participaram em 115 ações de formação promovidas pela entidade empregadora, sendo que o enfoque formativo recaiu em ações de formação de caráter técnico e em formações obrigatórias.

Pretendeu-se igualmente explorar a perceção subjetiva dos formandos acerca da qualidade das ações de formação em que participaram. Neste sentido, constatamos que a maioria dos formandos (61.48\%) a classificou com "bom", sendo que uma minoria (0,82\%) procede a uma avaliação negativa das ações de formação a que tiveram acesso. No que concerne aos efeitos decorrentes da participação em programas formativos promovidos pela empresa, constata-se que os aspetos positivos resultantes da formação reportam-se sobretudo a questões relacionadas com a oportunidade de desenvovimento pessoal e enriquecimento profissional. Não obstante, os efeitos decorrentes da participação em ações de formação estenderam-se a outras dimensões, como possibilitar a atualização de conhecimentos, maior iniciativa e dinamismo, elevação da autoeficácia, redução de erros, melhor integração na empresa, melhor avaliação de desempenho, maior capacidade para resolução de problemas profissionais e, por fim, maior cooperação e envolvimento na mudança. De um modo geral, os resultados sugerem que a formação é percecionada de forma positiva, assim como a transferência da formação, impugnando a discussão centrada na obrigatoriedade ou desmotivação face à formação profissional contínua. 
No entanto, quando questionados face à necessidade de melhoria no desempenho da sua atividade profissional, percebe-se que a maioria dos formandos considera que a sua performance poderá ser melhorada $(88,52 \%)$. Este resultado poderá ser parcialmente explicado tendo em consideração o facto de os indivíduos pertencerem a um escalão etário mais jovem (21-25 anos), o que pode determinar, em parceria com a antiguidade, uma associação influente neste domínio. De entre os motivos que concorrem e justificam a necessidade de formação nas organizações, vigoram habitualmente os de mudança e desenvolvimento, incluindo o desenvolvimento e aperfeiçoamento de competências. Assim, os programas de sugestões, o trabalho em equipa, a rotatividade do trabalho, a descentralização das decisões operacionais, a remuneração e a uniformização do status constituem alguns aspetos responsáveis pela elevação do desempenho (Domingues \& Neves, 2009).

\section{CONSIDERAÇÕES FINAIS}

Grosso modo, tem-se verificado uma crescente valorização do capital humano nas organizações, onde o investimento em formação profissional se tornou um imperativo permanente da vida organizacional, de forma a dar resposta aos novos desafios, nomeadamente de novas qualificações e de redução do desemprego. Apesar de os trilhos da investigação científica em torno da formação nas empresas terem assumido maior expressividade nas últimas décadas, verifica-se que esta se encontra imbuída de múltiplos significados e influi no aperfeiçoamento do desempenho profissional e na vantagem competitiva das organizações. Neste sentido, baseamonos numa visão humanista da educação, isto é, para além de oferecer pessoas qualificadas ao mundo do trabalho, a formação deverá servir como fim último o desenvolvimento daquelas e constituir-se como um agente de mudança, de redução das desigualdades e de coesão social. É importante a responsabilidade social empresarial na formação e qualificação profissional, através da aprendizagem ao longo da vida, constituindo esta um forte instrumento de empregabilidade, de exercício da cidadania e de integração social (Ramos, 2007).

Para a consumação dos objetivos que nos propusemos analisar, tentou-se articular as necessidades da organização com as expectativas dos indivíduos, sob um prisma global e participativo, constituindo um alerta para a sensibilização da permeabilidade institucional perante novos olhares e perspetivas. Nesta linha de pensamento, tem-se verificado que a capacidade de autoavaliação que leva as pessoas a conseguir formular necessidades de formação é raramente trabalhada no quotidiano das organizações (Rebelo, 2013) e muitas destas não dispõem ainda de políticas de formação formalizadas (Véro \& Sigot, 2017). Assim sendo, revela-se de suma importância redirecionar o foco da formação para um cariz mais transversal, que contemple as necessidades e expectativas de desenvolvimento pessoal e profissional dos trabalhadores. Interessa-nos, pois, discutir a pertinência de uma perspetiva hieraquicamente descentralizada, orientada para uma lógica de organização horizontal e democrática, onde as necessidades formativas possam ser discutidas e consciencializadas num processo participativo de decisão (Rebelo, 2013). 
Através do presente estudo, foi possível constatar que as práticas de socialização permitem aos novos colaboradores desenvolverem perceções de autoeficácia superiores e uma melhor adaptação e ajustamento ao novo papel. Consequentemente, os colaboradores revelam-se mais empenhados e implicados com a organização e com a função que protagonizarão, conduzindo à redução de intenção de turnover. Deste modo, concluímos que a formação nesta organização é contemplada de diversas formas, notabilizando-se a formação on-the-job e a formação em sala, apostando na realização de um continuum formativo, em oposição às ações de formação realizadas pontualmente. Verifica-se, de igual modo, a relação positiva entre satisfação no trabalho, envolvimento dos colaboradores, retenção e vontade de permanecer destes na empresa, e a perceção da formação recebida (Fletcher, Alfes \& Robinson, 2016).

No que concerne às limitações do presente trabalho, consideramos que o principal limitador está relacionado com o fator idade dos vendedores inquiridos, o qual tem um impacto significativo nos resultados obtidos. Trata-se, na sua maioria, de jovens, com informação relativamente escassa acerca da formação profissional e da sua importância em contexto organizacional. Por esse motivo, talvez não estejam habituados a verbalizar as suas reais necessidades e expectativas. Paralelamente, os participantes encontram-se em diferentes estádios de integração na empresa, pelo que há uma tendência para percecionarem a realidade organizacional de forma também diferenciada, isto é, indivíduos mais velhos e com tempo de serviço superior parecem deter uma perceção mais fidedigna do contexto e das práticas formativas levadas a cabo na empresa.

Futuramente, seria importante acompanhar os formandos após a realização das formações, recorrendo ao uso de feedback através de entrevista ou observação on-the-job, como forma de avaliar o impacto da formação no quotidiano dos formandos, procurando fortalecer o marketing de iniciativas formativas.

\section{REFERÊNCIAS}

Almeida, A. J., Alves, N., Bernardes, A. \& Neves, A. (2008). Estruturas e práticas de formação profissional das médias e grandes empresas em Portugal. VI Congresso Português de Sociologia. Mundos Sociais: Saberes e Práticas. Universidade Nova de Lisboa, Faculdade de Ciências Sociais e Humanas, Lisboa, 1-20.

Bardin, L. (1995). Análise de conteúdo. Lisboa: Edições 70.

Bernardes, A. (2008). Políticas e práticas de formação em grandes empresas - Situação atual e perspetivas futuras. Sísifo. Revista de Ciências da Educação, 6, 57-70.

Bernardes, A. (2013). Políticas e práticas de formação em grandes empresas. Porto: Porto Editora.

Caetano, A. (Coord.). (1999). Mudança Organizacional e Gestão de Recursos Humanos. Lisboa: Observatório do Emprego e Formação Profissional.

Camera, P., Guerra, P., \& Rodrigues, J. (2007). Novo Humanator, Recursos Humanos e Sucesso Empresarial. (1 1 Ed.). Lisboa: Dom Quixote.

Canário, R. (1997). Formação e situações de trabalho. Porto: Porto Editora. 
Canário, R. (1999). Educação de adultos. Um Campo e uma Problemática. Lisboa: EDUCA.

Cantarello, S., Filippini, R., \& Nosella, A. (2012). Linking human resource management practices and customer satisfaction on product quality. The International Journal of Human Resource Management, 23(18), 3906-3924.

Cardim, J. (2005). Formação profissional: problemas e políticas. Lisboa: Universidade Técnica de Lisboa. Instituto Superior de Ciências Sociais e Políticas.

Cardim, J. (2009). Gestão da Formação nas Organizações. Lisboa: Lidel - Edições Técnicas, Lda.

Cardoso, L. (1997). Gestão Estratégica das Organizações. Lisboa: Ed. Verbo.

Ceitil, M. (2004). Sociedade, Gestão e Competências. Lisboa: Ed. Silabo.

Chiavenato, I. (1998). Recursos Humanos. São Paulo: Atlas SA.

Crowell, C., Hantula, D., \& McArthur, K. (2011). From job analysis to performance management: a synergistic rapprochement to organizational effectiveness. Journal of organizational behavior, 31, 316-332.

Cruz, J. (1998). Formação profissional em Portugal: do levantamento de necessidades à avaliação. Lisboa: Edições Sílabo.

Cunha, M., Rego, A., Cunha, R., Cardoso, C., Marques, C., \& Gomes, J. (2010). Manual de Gestão de Pessoas e do Capital Humano. ( 2a ed.). Lisboa: Edições Sílabo.

Domingues, I., \& Neves, J. (2009). Tecnologia, gestão da qualidade e dos recursos humanos: análise sociológica. Ermesinde: Edições Ecopy.

Dubar, C. (2015). La formation professionnelle continue. Paris: La Découverte.

Dupray, A., Guillemot, D., \& Melnik-Olive (2017). Introduction : La formation continue en contexte: I'entreprise et ses salariés au cœur des enjeux. Formation Emploi, 137, 7-14.

Fletcher, L., Alfes, K., \& Robinson, D. (2016). The relationship between perceived training and development and employee retention: the mediating role of work attitudes. The International Journal of Human Resource Management, DOI:10.1080/09585192.2016.1262888.

Fonseca, M. (2012). Estratégias empresariais, práticas de gestão e desenvolvimento de recursos humanos. Atas dos Ateliers do Vo Congresso Português de Sociologia, Lisboa, 82-89.

França, V. (2013). Contributo da formação para o elevado desempenho organizacional: um estudo de caso de uma entidade formadora. Dissertação de Mestrado. Universidade de Coimbra, Faculdade de Economia, Coimbra.

Franco, M., \& Ferreira, T. (2007). Um estudo de caso sobre as organizações que aprendem. Comportamento Organizacional e Gestão, 13(2), 169-189.

Gomes, J., Cunha, M., Rego, A., Cunha, R., Cabral-Cardoso, C., \& Marques, C. (2008). Manual de gestão de pessoas e do capital humano. Lisboa: Edições Sílabo.

Harrison, R. (2009). Learning and development. (5th ed.). London: Chartered Institute of Personnel and Development. 
Klarin, M. (2016). Conceptual challenges in understanding innovative education in organizational context. International Journal of Cognitive Research in Science, Engineering and Education (IJCRSEE), 4 (1), 67-72.

Marques, C. (2008). Manual de Gestão de Pessoas e do Capital Humano. (1ạ Ed.). Lisboa: Sílabo.

Monteiro, L. (2009). O impacto das Best Practices de gestão do capital humano no desempenho das 500 maiores e melhores empresas em Portugal. Dissertação de Mestrado. Universidade do Minho, Braga.

Neta, O. M. M. (2016). A configuração do campo da educação profissional no Brasil. Holos, 6, 5055.

Ramos, M.C.P. (2003). Ação Social na área do Emprego e da Formação Profissional. Lisboa: Universidade Aberta.

Ramos, M. C. (2007). Aprendizagem ao longo da vida. Instrumento de empregabilidade e integração social. Revista Portuguesa de Pedagogia, dez., 299-333.

Rebelo, M. (2013). Análise de Necessidades de Formação: aproximações e percursos em torno de um caso. Relatório de Estágio de Mestrado. Universidade do Minho, Braga.

Rodrigues, S. P., \& Alves, N. (2016). A indelével relação entre trabalho e formação: o caso do centro de formação de uma grande empresa. Revista Portuguesa de Pedagogia, 50 (1), 117138.

Santelmann, P. (2017). Analyse du travail et ingénierie de formation: un lien indéfectible. Revue Education Permanente, 1, 21-32.

Sousa, M. J., Duarte, T., Sanches, P. G., \& Gomes, J. (2006). Gestão de recursos humanos - métodos e práticas. (9.a ed.). Lisboa: Editora Lidel.

Thomas, C. H., \& Lankau, M. J. (2009). Preventing Burnout: The Effects of LMX and Mentoring on Socialization, Role Stress, and Burnout. Human Resource Management, 48 (3), 417-432.

Torres, L., \& Palhares, J. (2008). Cultura, formação e aprendizagens em contextos organizacionais. Revista Crítica de Ciências Sociais, 83, 99-120.

Véro, J., \& Sigot, J.-C. (2017). Comment les entreprises s'organisent pour mettre les salariés en capacité de se former. Formation Emploi, 137, 73-95. 